\title{
Possible Involvement of Inefficient Cleavage of Preprovasopressin by Signal Peptidase as a Cause for Familial Central Diabetes Insipidus
}

\author{
Masafumi Ito, Yutaka Oiso, Takashi Murase, Kunikazu Kondo, Hidehiko Saito, Tadanobu Chinzei, " Marco Racchi," \\ and Mark O. Lively ${ }^{\ddagger}$ \\ First Department of Internal Medicine, Nagoya University School of Medicine, Nagoya, Aichi 466 Japan; *Internal Medicine, \\ Kakogawa Municipal Hospital, Kakogawa, Hyogo 675 Japan; and ${ }^{\ddagger}$ Department of Biochemistry, Bowman Gray School of Medicine, \\ Wake Forest University, Winston-Salem, North Carolina 27157
}

\begin{abstract}
A transition of $G$ to $A$ at nucleotide position 279 in exon 1 of the vasopressin gene has been identified in patients with familial central diabetes insipidus. The mutation predicts an amino acid substitution of Thr (ACG) for Ala (GCG) at the COOH terminus of the signal peptide in preprovasopressin (preproVP). Translation in vitro of wild-type and mutant $m R N A s$ produced 19-kD preproVPs. When translated in the presence of canine pancreatic rough microsomes, wild-type preproVP was converted to a 21-kD protein, whereas the mutant mRNA produced proteins of $21 \mathrm{kD}$ and $23 \mathrm{kD}$. $\mathrm{NH}_{2}$-terminal amino acid sequence analysis revealed that the $21-\mathrm{kD}$ proteins from the wild-type and the mutant were proVPs generated by the proteolytic cleavage of the 19-residue signal peptide and the addition of carbohydrate. Accordingly, mutant preproVP was cleaved at the correct site after Thr-19, but the efficiency of cleavage by signal peptidase was $<25 \%$ that observed for the wild-type preproVP, resulting in the formation of a predominant glycosylated but uncleaved $23-\mathrm{kD}$ product. These data suggest that inefficient processing of preproVP produced by the mutant allele is possibly involved in the pathogenesis of diabetes insipidus in the affected individuals. (J. Clin. Invest. 1993. 91:25652571.) Key words: direct sequencing • cell-free translation • signal peptide $\bullet$ provasopressin $\bullet$ amino acid sequence analysis
\end{abstract}

\section{Introduction}

Preprovasopressin (preproVP) ${ }^{1}$ is encoded by the VP gene on chromosome 20 (1). Exon 1 of the VP gene encodes the putative signal peptide, $\mathrm{VP}$, and the $\mathrm{NH}_{2}$-terminal region of neuro-

Part of this work was presented at the Satellite Symposium of the Ninth International Congress of Endocrinology, Spa-Liège, Belgium, 6-10 September 1992, and at the Meeting of the International Committee on Proteolysis, Williamsburg, VA, 18-23 October 1992.

Address correspondence to Masafumi Ito, M.D., The First Department of Internal Medicine, Nagoya University School of Medicine, 65 Tsurumai-cho, Showa-ku, Nagoya Aichi 466, Japan. Dr. Racchi's present address is Institute of Pharmacological Science, University of Milan, Faculty of Pharmacy, Milan, Italy.

Received for publication 25 June 1992 and in revised form 12 January 1993.

1. Abbreviations used in this paper: $\mathrm{CDI}$, central diabetes insipidus; NP, neurophysin II; nt, nucleotide; preproVP, preprovasopressin; PVDF, polyvinylidene difluoride.

J. Clin. Invest.

(C) The American Society for Clinical Investigation, Inc.

0021-9738/93/06/2565/07 \$2.00

Volume 91, June 1993, 2565-2571 physin II (NP). Exon 2 gives rise to the central region of NP and exon 3 accounts for the $\mathrm{COOH}$-terminal region of NP and glycoprotein (2). ProVP is generated by the removal of the signal peptide from preproVP and the addition of carbohydrate to its glycoprotein domain in magnocellular neurons in the hypothalamus. Additional posttranslational processing occurs within neurosecretory vesicles during transport of the precursor proteins to axon terminals in the posterior pituitary, yielding VP, NP, and glycoprotein (3).

Central diabetes insipidus (CDI) results from decreased levels of VP in plasma. One of its categories, familial CDI, is usually transmitted as an autosomal dominant trait (4-6). We have previously reported a mutation in exon 2 of the VP gene in patients with familial CDI (6). According to the mutation, an amino acid substitution in the NP domain of preproVP was predicted. In a separate pedigree of familial CDI, we have now identified a mutation in exon 1 of the VP gene that leads to an amino acid substitution at the $\mathrm{COOH}$ terminus ( -1 position ) of the secretory signal peptide in preproVP.

Normally, the preprohormone is recognized by signal peptidase and its signal peptide is cleaved during cotranslational translocation, releasing the prohormone into the lumen of the endoplasmic reticulum. Signal peptides typically consist of three domains, including a positively charged $\mathrm{NH}_{2}$ terminus, a hydrophobic core, and a polar $\mathrm{COOH}$-terminal region $(7,8)$. Their structural features are critical for the translocation of secretory proteins and their cleavage by signal peptidase $(9,10)$.

To date, there are only two examples of naturally occurring mutations within the signal peptide that result in human diseases other than familial CDI (11-13). An amino acid substitution within the hydrophobic core of the signal peptide of preproparathyroid hormone has been linked to a form of familial hypoparathyroidism (11). Similarly, a severe bleeding diathesis results from a substitution at the -3 position of the signal peptide of coagulation Factor $\mathrm{X}_{\text {Santo Domingo }}(12,13)$. In each case, the alteration of the signal peptide structure results in the failure to secrete the affected protein.

The mutation identified in the this study occurs at the -1 position of preproVP, the $\mathrm{COOH}$-terminal residue, that immediately precedes the signal peptidase cleavage site. We have established the linkage of this mutation with five patients with familial CDI and analyzed the effect of the amino acid substitution on the biosynthesis of VP.

\section{Methods}

Materials. Restriction enzymes, reverse transcriptase, and bacteriophage T4 DNA polymerase were purchased from either Boehringer Mannheim Corp., Indianapolis, IN, or Takara Shuzo Co. Ltd., Kyoto, Japan. The Sequenase kit used for DNA sequencing was from United 
States Biochemical Corp., Cleveland, OH. The oligonucleotide-directed in vitro mutagenesis system, $\left[{ }^{35} \mathrm{~S}\right] \mathrm{dCTP}$, and $\left[{ }^{3} \mathrm{H}\right] \mathrm{Phe}$ were obtained from Amersham Corp., Arlington Heights, IL. Escherichia coli XL1-Blue, pBluescript II SK + phagemid vector, and $\mathrm{mCAP}^{\mathrm{TM}} \mathrm{mRNA}$ capping kit were from Stratagene Inc., La Jolla, CA. Rabbit reticulocyte lysate and canine pancreatic rough microsomes were purchased from Promega Corp., Madison, WI. Polyvinylidene difluoride (PVDF) membrane (ProBlott) was from Applied Biosystems, Inc., Foster City, CA. Oligonucleotides were synthesized using a DNA synthesizer (model 391A; Applied Biosystems, Inc.). Antibodies directed against rat neurophysin are a gift from Dr. Alan G. Robinson, Department of Medicine, University of Pittsburgh School of Medicine, Pittsburgh, PA (14).

Subjects. In a Japanese pedigree of familial CDI (Fig. 1), seven subjects spanning four generations were supposed to be affected by this disorder, because they each presented histories of symptoms of DI including polyuria, polydipsia, and thirst since their childhood. Upon initial examination, the basal urine osmolalities of affected subjects I, II, and III were 87,94 , and $88 \mathrm{mOsm} / \mathrm{kg}$, respectively. Based upon the impaired response of their urine osmolalities to water deprivation and good response to exogeneously administered VP, they were diagnosed as CDI. $8 \mathrm{yr}$ after the initial diagnosis, infusion tests with $5 \%$ hypertonic saline were performed to evaluate the severity of DI (Fig. 2). The basal plasma levels of VP in subjects I, II, and III were $0.2,0.6$, and 0.6 $\mathrm{pg} / \mathrm{ml}$, respectively. After stimulation by hypertonic saline, plasma osmolalities sufficiently increased, but the VP levels were $0.6,0.5$, and $0.6 \mathrm{pg} / \mathrm{ml}$ in subjects I, II, and III, respectively. DI of all three patients has been controlled by administration of 1-desamino-8-D-arginine vasopressin. Clinical data concerning the severity of DI in affected subjects V and VII are not available. Unaffected subjects IV, VI, and VIII have not reported symptoms of DI. Peripheral blood specimens were obtained for extraction of genomic DNA from five affected subjects ( $I$, II, III, V, and VII), three unaffected subjects (IV, VI, and VIII), and 50 unrelated normal Japanese subjects. Informed consent was obtained from all subjects studied.

Direct sequencing of VP gene. Amplification of the VP gene from genomic DNA by PCR and direct sequencing of the amplified doublestranded DNA were performed as previously described (6).

Restriction enzyme analysis. PCR-amplified fragments of the VP gene were digested with PmaCI and AcclI according to the manufacturer's instructions and the digests were analyzed on $8 \%$ polyacrylamide gels.

Preparation of wild-type VP cDNA. The first strand cDNA was synthesized using primer $A$ by reverse transcriptase from the mRNA extracted from the tissues of a VP-producing tumor associated with inappropriate secretion of antidiuretic hormone (Fig. 3). The VP-producing tumor used was an undifferentiated esophageal carcinoma whose VP content was $59.6 \mathrm{ng} / \mathrm{g}$ dried tissue wt. The double-stranded cDNA was then amplified by PCR using primers $A$ and $B$ according to the conditions previously described (6). Primer A (GGCGGAGCTCTATTGTCCGTGCTGCAGGGGCGGGCG; nucleotide [nt] numbering is according to the previous report [2] $2322 \rightarrow 2287$ ) is located

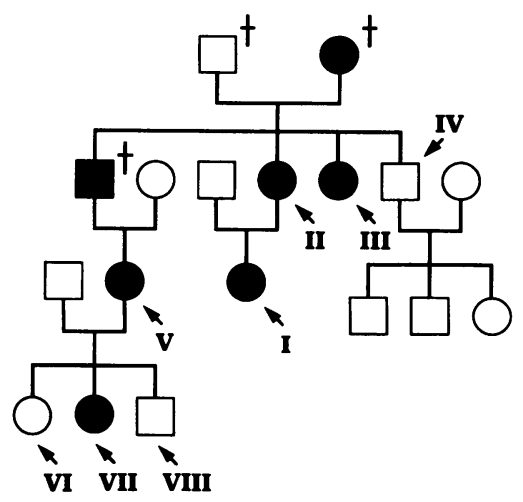

Figure 1. Pedigree of familial CDI. Squares and circles represent males and females, respectively. Affected subjects are shown by filled symbols. Arrows indicate subjects studied. Deceased subjects are shown by cross.

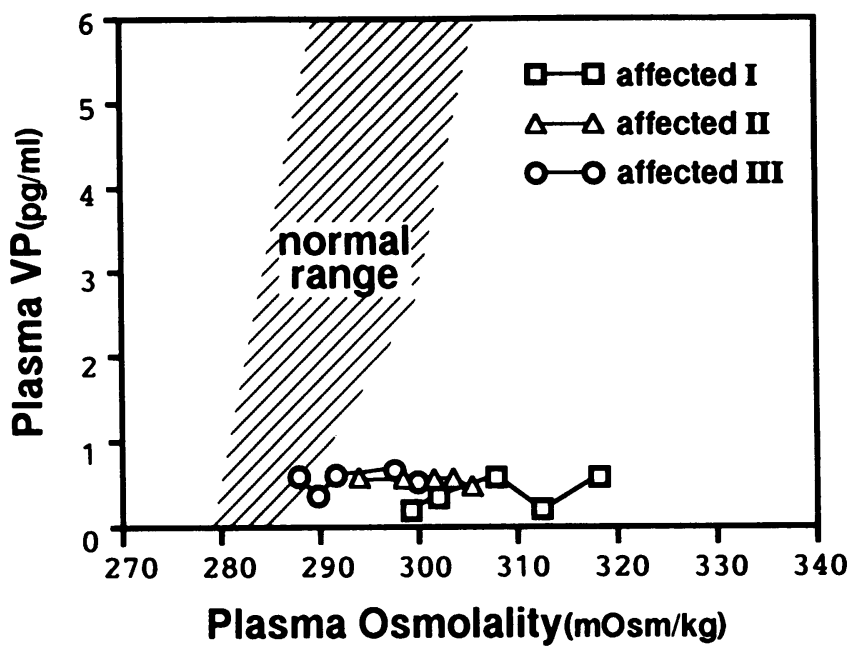

Figure 2. Relationship between plasma VP levels and plasma osmolalities during infusion of $5 \%$ hypertonic saline. Three affected subjects (I, II, and III) in a pedigree of familial CDI are diagnosed as complete DI.

in the 3'-untranslated region and primer B (ACAGTCTAGACAAGCAGTGCTGCATACGGGGTCCAC; nt $175 \rightarrow 210$ ) is in the 5 '-untranslated region. Primers A and B were designed to generate SacI (GAGCTC) and XbaI (TCTAGA) sites at each end of the amplified double-stranded cDNA, respectively. After digestion by XbaI and SacI, the cDNA was inserted into XbaI- and SacI-digested bacteriophage M13 mp18 vector and $E$. coli JM101 cells were transformed by the ligated materials. Plaques containing phage with cDNA inserts were identified by restriction enzyme analysis using XbaI and SacI and confirmed by the dideoxy-mediated chain termination method (15).

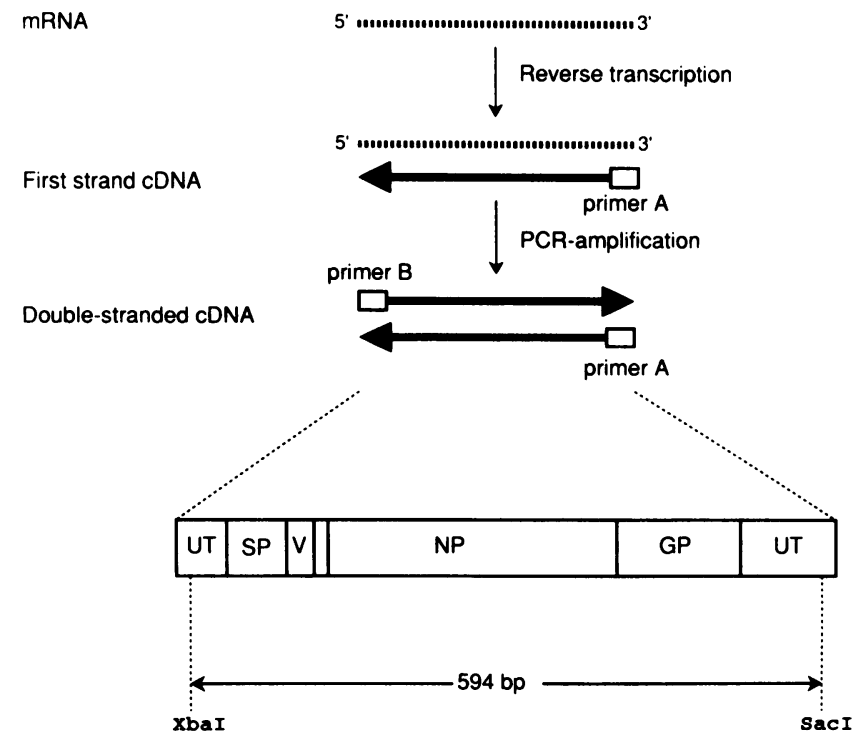

Figure 3. Strategy for preparation of human wild-type VP cDNA. The first strand cDNA is synthesized by reverse transcriptase using primer A (see Methods for primer sequences). The double-stranded cDNA is amplified by PCR using primers A and B. As primers A and B located in untranslated regions are designed to generate SacI and $\mathrm{Xbal}$ sites, respectively, digestion of the double-stranded cDNA by the enzymes yields a 594-bp fragment. The cDNA encodes the signal peptide (SP), VP (V), tripeptide bridge (-Gly-Lys-Arg-), neurophysin II (NP), and glycoprotein (GP), in this order. 
Preparation of mutant VP cDNA. An M13 mp18 vector containing the mutant cDNA was synthesized from the single-stranded M13 mp18 vector containing wild-type cDNA by the oligonucleotidedirected in vitro mutagenesis system (16).

Preparation of templates for transcription in vitro. Wild-type and mutant cDNAs prepared by $\mathrm{XbaI}$ and SacI digestion of replicative forms of M13 mp18 vector were ligated into Xbal- and SacI-digested pBluescript II SK + vectors before transformation of $E$. coli XL1-Blue cells. Colonies containing appropriate plasmids were selected by restriction enzyme analysis ( $\mathrm{XbaI}$ and SacI; SacI; and PmaCI). After largescale preparation, $\mathrm{CsCl}$ banding was carried out twice. The purified plasmids were linearized by cleavage with SacI. The protruding 3'-termini produced by digestion with SacI were filled in by treating with bacteriophage T4 DNA polymerase.

Transcription in vitro. As cDNA inserts are located downstream of a T7 RNA transcription promoter, transcription in vitro was performed using T7 RNA polymerase and reagents provided in the capping kit. To confirm the quality of synthesized, capped mRNAs, they were analyzed by denaturing acrylamide gel electrophoresis.

Translation in vitro. Wild-type and mutant capped mRNAs were translated in vitro by nuclease-treated rabbit reticulocyte lysate containing $\left[{ }^{3} \mathrm{H}\right]$ Phe in the absence or presence of increasing amounts of canine pancreatic rough microsomes (17). Translation reactions were carried out at $30^{\circ} \mathrm{C}$ for $60 \mathrm{~min}$. After translation reactions, translation products were immunoprecipitated with anti-rat neurophysin antibodies. Immunoprecipitates were analyzed by SDS PAGE using $15 \%$ acrylamide gels (18) and the amount of translation product was quantified by scanning the band density of the autoradiograms using a laser densitometer (Ultrascan XL; LKB Instruments, Inc., Gaithersburg, MD).

$\mathrm{NH}_{2}$-terminal amino acid sequence analysis. For $\mathrm{NH}_{2}$-terminal amino acid sequence analysis of $\left[{ }^{3} \mathrm{H}\right] \mathrm{Phe}$-labeled preproVP processing products, the contents of microsomal vesicles were recovered by sedimentation at $109,000 \mathrm{~g}_{\mathrm{av}}$ in a tabletop ultracentrifuge (model TL100; Beckman Instruments, Inc., Fullerton, CA) after cell-free protein synthesis in the presence of canine pancreatic rough microsomes. The proteins were separated by SDS PAGE in $15 \%$ acrylamide gels and electrophoretically transferred to PVDF membranes. Labeled proteins were detected by autoradiography of the PVDF blots. The excised PVDF bands were subjected to automated sequential Edman degradation using an automated protein sequencer (model 475; Applied Biosystems, Inc.) (19). Amino acid derivatives produced by each sequencer cycle were analyzed for content of tritium by liquid scintillation counting.

\section{Results}

Identification of the mutation. In five affected subjects (I, II, III, V, and VII ), two bands of G and A were detected at nucleo-

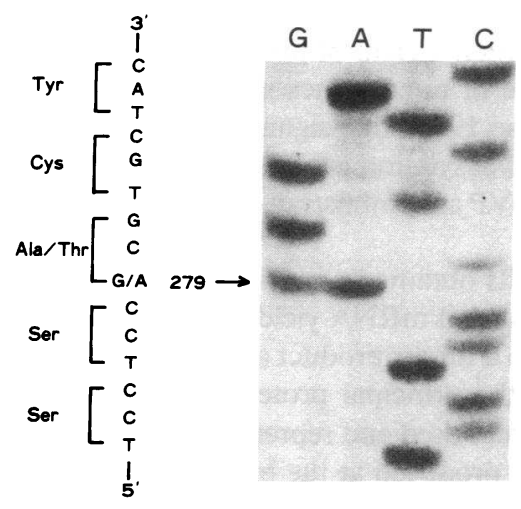

Figure 4. Direct sequence analysis of PCR-amplified VP gene. In five affected subjects, two bands of $\mathrm{G}$ and $\mathrm{A}$ were detected at nucleotide position 279. This mutation is a $\mathrm{G} \rightarrow \mathrm{A}$ transition and the affected subjects are heterozygous for the mutation. According to the mutation, an amino acid substitution of Ala (GCG) to Thr (ACG) is anticipated at the -1 position of the signal peptide in preproVP. The sequencing data from affected subject I are shown.
A

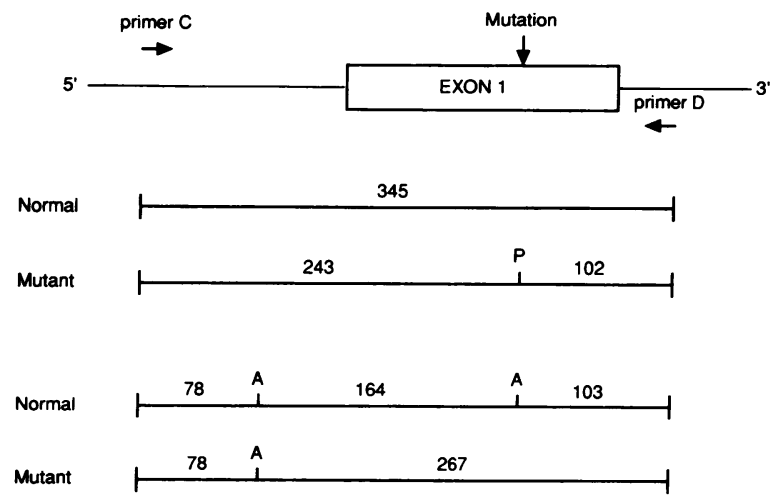

B

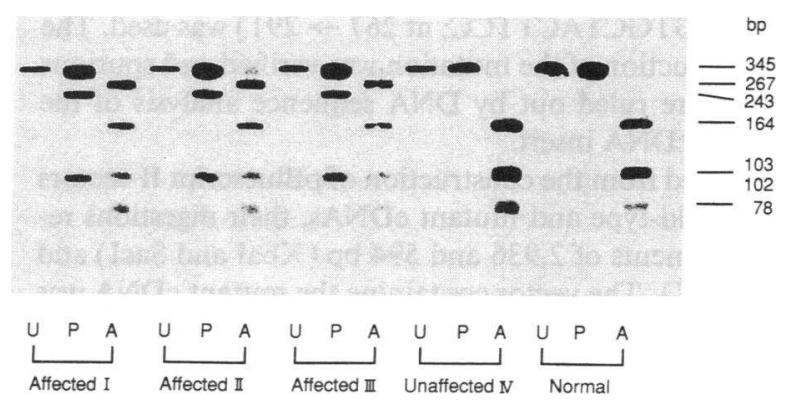

Figure 5. Restriction enzyme analysis of the VP gene. $(A)$ Restriction sites of a 345-bp fragment including the mutation site amplified by PCR using primers $C$ and $\mathrm{D}$ are shown. PmaCI $(P)$ digestion of amplified DNA from the mutant allele results in fragments of 243 and $102 \mathrm{bp}$. Amplified DNA from normal allele should not be digested. Accll $(A)$ digestion of amplified DNA from the mutant allele yields fragments of 267 and $78 \mathrm{bp}$, whereas that from the normal allele produces three fragments of 164,103 , and 78 bp. $(B)$ Polyacrylamide gel electrophoresis ( $8 \%$ acrylamide gel) of undigested $(U)$ and digested $(P$ and $A$ ) fragments is shown. Three affected subjects (I, II, and III) have both the mutant and normal alleles, whereas an unaffected subject (IV) and a normal subject do not have the fragments specific for the mutant allele.

tide position 279 in exon 1 of the VPgene. The sequencing data from affected subject $I$ are shown in Fig. 4. In each case, the mutation was a $G \rightarrow A$ transition and the affected subjects were heterozygous for the mutation. Three unaffected subjects (IV, VI, and VIII) did not possess the mutation (data not shown). The heterozygosity of the affected subjects was compatible with an autosomal dominant mode of inheritance observed in the family (Fig. 1).

The mutation introduced a restriction site for PmaCI (CGCGTG $\rightarrow$ CACGTG) and abolished a site for AccII (CGCG $\rightarrow$ CACG). As shown in Fig. $5 A$, a 345-bp fragment including the mutation site was amplified by PCR using primer C (TGCCTGAATCACTGCTGACCGCTGGGGACC; nt $38 \rightarrow$ 67) and primer D (GCTATGGCTGCCCTGAGATGGCCCACAGTG; nt $382 \rightarrow 353$ ) and was subjected to digestion by the restriction enzymes. It was anticipated that PmaCI digestion of amplified DNA from the mutant allele would result in fragments of 243 and $102 \mathrm{bp}$, whereas that from the normal allele should not be digested. AccII digestion of amplified DNA 
from the mutant allele was expected to yield fragments of 267 and $78 \mathrm{bp}$, whereas that from the normal allele should produce fragments of 164,103 , and $78 \mathrm{bp}$. Therefore, the 243- and 102-bp fragments from PmaCI digestion and the 267-bp fragment from AccII digestion were used as markers for the mutant allele. Judging from this method, affected subjects I, II, III, V, and VII had both the mutant and the normal alleles. Unaffected subjects IV, VI, and VIII and 50 unrelated normal Japanese subjects did not have the fragments specific for the mutant allele. Results of three affected subjects (I, II, and III), one unaffected subject (IV), and one normal subject are shown in Fig. 5 B.

Although the wild-type VP cDNA was synthesized from mRNAs of a VP-producing tumor, its nucleotide sequence was identical to the human VP cDNA sequence (20) and that deduced from the previous reports of human VP genomic sequence $(2,6)$. To synthesize a cDNA encoding the mutant form of preproVP, a mutagenic oligonucleotide (GCCTTCTCCTCCACGTGCTACTTCC; nt $267 \rightarrow 291$ ) was used. The correct introduction of the mutation was verified and spurious mutations were ruled out by DNA sequence analysis of the mutagenized cDNA insert.

As expected from the construction of pBluescript II vectors containing wild-type and mutant cDNAs, their digestions resulted in fragments of 2,936 and $594 \mathrm{bp}$ ( XbaI and SacI) and $3,530 \mathrm{bp}$ (SacI). The vector containing the mutant cDNA was cut by PmaCI to yield a 3,530-bp fragment, whereas that containing the wild-type cDNA was not cut by this enzyme (data not shown). As synthesized, capped $\mathrm{mRNAs}$ were visualized as single bands on denaturing acrylamide gels (data not shown), they were not degraded and were presumed to be suitable for translation in vitro.

Cotranslational processing of wild-type and mutant preproVPs. The initial stages of the protein secretory pathway can be reconstituted using cell-free translation of mRNAs in the presence of rough endoplasmic microsomes (vesicular fragments of the endoplasmic reticulum that form spontaneously upon cell homogenization). These microsomes contain functional systems for translocation across the lipid bilayer, proteolytic processing, and core glycosylation of nascent secretory proteins produced by cell-free protein synthesis (17). Currently available evidence shows that the microsomal signal peptidase is a highly conserved enzyme found in eukaryotic species from yeast to higher mammals $(21,22)$. When eukaryotic microsomal signal peptidases from different species have been compared, their substrate specificities have been found to be essentially indistinguishable. For example, analysis of the cleavage of mutated model signal peptides by purified hen oviduct signal peptidase and canine pancreatic microsomal signal peptidase revealed no differences in specificity of cleavage (23, 24 ). Therefore, it is reasonable to expect that canine pancreatic microsomal signal peptidase is an accurate model system for examining the effects of naturally occurring mutations on the processing of human secretory proteins.

Consistent with results of cell-free translation of poly $(\mathrm{A})^{+}$ RNA from human hypothalami (20) and bovine hypothalami (25), translation of wild-type and mutant VP mRNAs in the absence of microsomes each yielded preproVP, a 19-kD product that was immunoprecipitable with anti-rat neurophysin antibodies (Fig. 6). When cell-free protein synthesis was performed in the presence of increasing amounts of microsomes $(0.2,0.5$, and $1.0 \mathrm{U}$; one unit is defined as one microliter of a

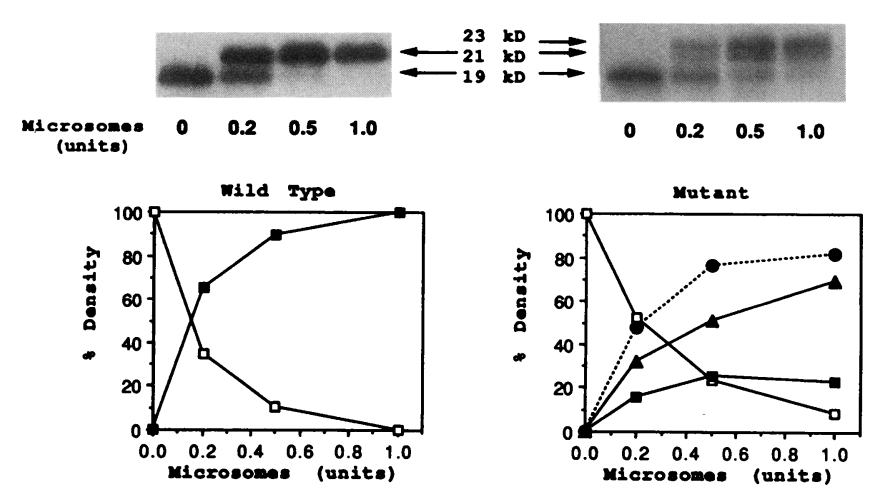

Figure 6. Cotranslational processing assays with wild-type and mutant preproVPs. Wild-type and mutant mRNAs encoding preproVP were synthesized by transcription of their respective cDNAs in vitro. The transcribed mRNAs were translated at $30^{\circ} \mathrm{C}$ for $60 \mathrm{~min}$ in a rabbit reticulocyte lysate cell-free protein synthesis system in the absence or presence of $0.2,0.5$, or $1.0 \mathrm{U}$ of canine pancreatic rough microsomes. The reaction products were immunoprecipitated with anti-rat neurophysin antibodies and separated by SDS PAGE in 15\% acrylamide gels. The upper panels show the autoradiograms of the dried gels obtained for the wild-type mRNAs (left) and mutant mRNAs (right). The estimated molecular masses of the protein bands are indicated by the arrows. The autoradiograms were quantified by scanning densitometry and the density of each band was plotted as a percentage of the total radioactivity in each lane as follows: $19-\mathrm{kD}$ products (open squares); 21-kD products (filled squares); $23-\mathrm{kD}$ products (filled triangles); sum of 21 - and $23-\mathrm{kD}$ products (filled circles).

microsome suspension having an $A_{280 \mathrm{~nm}}=50$; [17]), the wildtype mRNA produced a single, immunoprecipitable 21-kD protein product (Fig. 6). The amount of $21-\mathrm{kD}$ protein produced was directly related to the concentration of microsomes present in the translation mixture and $100 \%$ processing was observed in the presence of $1.0 \mathrm{U}$ of microsomes. Upon centrifugation at $109,000 g_{\mathrm{av}}$, the $21-\mathrm{kD}$ protein sedimented with the microsomes (data not shown) indicating that these molecules were translocated into the interior of the vesicles during synthesis (23).

To identify the $21-\mathrm{kD}$ translation product, amino acid sequence analysis was performed using the radiosequencing method described in Methods. $\left[{ }^{3} \mathrm{H}\right]$ Phe was released only at cycle 3 in the first 20 cycles of Edman degradation (Fig. 7, top panel). This pattern of release of $\left[{ }^{3} \mathrm{H}\right] \mathrm{Phe}$ is consistent with the $\mathrm{NH}_{2}$-terminal sequence of proVP arising from cleavage of preproVP by signal peptidase at the normal site after Ala-19 $(2,6$, $20)$. The increase in molecular weight of proVP $(2 \mathrm{kD})$ upon translation in the presence of microsomes is most likely the result of the removal of the 19-residue signal peptide $(2 \mathrm{kD})$ and the addition of core glycosylation at the single Asn-linked glycosylation site of preproVP as demonstrated previously with bovine proVP (25).

In contrast to the results obtained with the wild-type construct, translation of the mutant mRNA yielded a major product at $23 \mathrm{kD}$ in addition to a minor product at $21 \mathrm{kD}$ (Fig. 6). The $23-\mathrm{kD}$ product was the principal protein made at each concentration of microsomes used and represented $69 \%$ of the immunoreactive products produced at the highest concentration of microsomes tested. As with the wild-type mRNA, both translation products were recovered with the microsome pellet after centrifugation at $109,000 g_{a v}$ indicating that both higher 


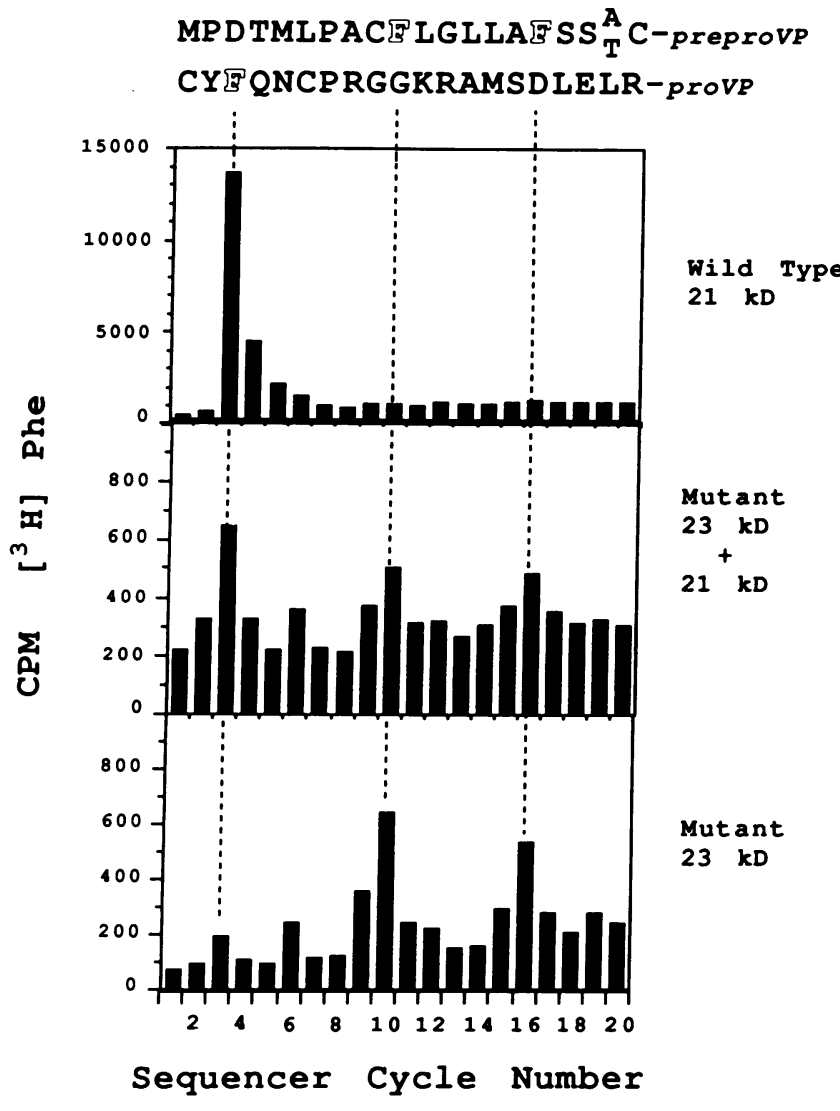

Figure 7. Amino acid sequence analysis of translation products. Cellfree protein synthesis reactions programmed with either wild-type or mutant mRNAs were performed in the presence of canine pancreas rough microsomes and $\left[{ }^{3} \mathrm{H}\right] \mathrm{Phe}$. The translation products were sedimented by centrifugation at $109,000 g_{\mathrm{av}}$, solubilized with SDS sample buffer and subjected to SDS PAGE in $15 \%$ acrylamide gels. After electrophoresis, the proteins were transferred electrophoretically to PVDF membranes and the protein bands were detected by autoradiography and excised from the PVDF membrane. The excised bands were directly subjected to automated amino acid sequence analysis (19). The tritium content of the amino acid derivatives released by each cycle of Edman degradation was determined by liquid scintillation counting and plotted versus the amino acid position. The amino acid sequences of preproVP and proVP are indicated at the top of the figure. (Top panel) Wild-type 21-kD band; (middle panel) mutant 21- and 23-kD bands sequenced together; (bottom panel) mutant 23kD band.

molecular mass forms had become associated with the microsomal vesicles (data not shown).

It proved to be impossible to obtain amino acid sequence analysis data representing either of 21 - and 23-kD bands alone because of their very close electrophoretic migration. To optimize the amounts of each processed form present and to maximize the resolution of each, translations were performed with $<0.5 \mathrm{U}$ of microsomes present (see Fig. 6). This approach produced a lower total yield of ${ }^{3} \mathrm{H}$ incorporated into the processed mutant bands compared to the wild-type, but we were able to obtain useful sequence data. Although we were unable to directly determine the sequence of the mutant $21-\mathrm{kD}$ protein in the absence of the $23-\mathrm{kD}$ protein, $\left[{ }^{3} \mathrm{H}\right] \mathrm{Phe}$ was released at cycles 3,10 , and 16 , when both bands were purposely sequenced together (Fig. 7, middle panel). This pattern is consis- tent with the amino acid sequence of a mixture of proVP and preproVP $(2,6,20)$. When the more abundant $23-\mathrm{kD}$ band was independently sequenced by carefully cutting the upper portion of the doublet from the PVDF blot, the peak of $\left[{ }^{3} \mathrm{H}\right] \mathrm{Phe}$ at cycle 3 was significantly reduced (Fig. 7, bottom panel) allowing us to conclude that the peak observed at cycle 3 was contributed by the $21-\mathrm{kD}$ product. Taking account of the relative increase in molecular mass compared to preproVP, we concluded that the $21-\mathrm{kD}$ product was proVP identical to the wild-type proVP and that the $23-\mathrm{kD}$ product was uncleaved, glycosylated preproVP.

It is important to point out that the large difference in the yield of $\left[{ }^{3} \mathrm{H}\right] \mathrm{Phe}$ in each sequencer analysis (compare panels in Fig. 7) is the result of the methods of sample preparation as described above and not due to any difference in the relative efficiency of translation of the two mRNAs. In 11 different cell-free translation reactions, the incorporation of $\left[{ }^{35} \mathrm{~S}\right] \mathrm{Cys}(6$ reactions), $\left[{ }^{3} \mathrm{H}\right]$ Pro ( 1 reaction), and $\left[{ }^{3} \mathrm{H}\right]$ Phe (4 reactions) into wild-type and mutant preproVPs was consistently very similar when equal concentrations of wild-type and mutant mRNAs were used (data not shown). Thus, we conclude that there is no significant difference in translation efficiency of these two mRNAs in vitro.

Accordingly, the translation of the mutant VP mRNA in the presence of microsomes resulted in translocation of the preproVP into the vesicles and efficient glycosylation of the precursor. However, cleavage of the mutant preproVP by signal peptidase was inefficient as $<25 \%$ of the translocated molecules were cleaved under these conditions (Fig. 6). Although cleavage was inefficient, the small amount of preproVP processed by signal peptidase was cleaved at the normal site after Thr-19.

\section{Discussion}

We have identified a $\mathrm{G} \rightarrow \mathrm{A}$ transition at nucleotide position 279 in exon 1 of the VP gene in patients with familial CDI. This mutation was segregated between five affected subjects and three unaffected subjects in the family and was not detected in normal Japanese subjects studied. These results strongly suggested that this mutation was responsible for the deficiency of VP in the affected subjects. The mutation causes the substitution of Thr (ACG) for Ala (GCG) at the -1 position, the $\mathrm{COOH}$ terminus, of the signal peptide of preproVP.

Mutations associated with familial CDI which have been reported up to the present are in exon 2 encoding the NP domain within the VP gene. We have previously reported an amino acid substitution of Ser for Gly at position 57 in the NP domain (6). The results of that study strongly suggested that a single amino acid replacement in that region of preproVP could be a cause for DI and that this domain is critical for VP secretion. This speculation was strengthened by a recent report in which a substitution of Val for Gly at position 17 in the NP domain was described in a Dutch family with autosomal dominant CDI (26).

In contrast to these previous reports, the mutation identified in the present study predicted an amino acid substitution at the $\mathrm{COOH}$ terminus of the signal peptide, immediately preceding the VP domain. Because this mutation would not be expected to be present in the mature secreted products, we postulated that its effect must be exerted on the initial stage of 
precursor synthesis. Studies with model secretory proteins in vitro have revealed different effects that can result from alteration of the amino acid sequences of signal peptide (27). Amino acid substitutions within the signal peptide can block targeting to the endoplasmic reticulum, translocation across the bilayer, cleavage by signal peptidase, or may have no measurable effect.

Only two other cases have been reported in which naturally occurring mutations within signal peptides have been shown to result in human disease. A form of familial hypoparathyroidism is associated with the substitution of Arg for Cys within the hydrophobic core of the signal peptide of preproparathyroid hormone (11). This mutation at amino acid position -8 blocks targeting and/or cleavage by signal peptidase of the nascent preproparathyroid hormone and thus blocks secretion of the mature hormone. In the second example, a severe bleeding diathesis is caused by the substitution of Arg for Gly at amino acid position -3 of the signal peptide of coagulation Factor $X$ (12). The afflicted patient has a severe deficiency of Factor $\mathrm{X}$ which is caused by the failure of signal peptidase to cleave the mutant Factor $\mathrm{X}_{\text {Santo Domingo }}(13)$. Targeting and translocation of the Factor $\mathrm{X}$ into the endoplasmic reticulum are unaffected but the precursor of Factor X remains in an intracellular compartment and is not secreted.

Two mutations within human proteins have been identified that cause signal peptidase to cleave at alternate sites but without apparent pathological effect on the function of the affected proteins $(28,29)$. Antithrombin Dublin has a mutation at the -3 position of the signal peptide that results in substitution of Glu for the normally occurring Val (28). The effect of this mutation is to redirect cleavage by signal peptidase to a site two amino acid residues toward the $\mathrm{COOH}$ terminus from the normal site leading to secretion of antithrombin that lacks its first two amino acids. There is no apparent clinical significance resulting from this mutation. Similarly, albumin Redhill is a glycoprotein variant of human serum albumin in which a substitution of Cys for Arg at the penultimate position of the "pro" peptide (not the signal peptide) apparently redirects cleavage by signal peptidase to a new site five residues toward the normal $\mathrm{NH}_{2}$ terminus of mature albumin (29). This cleavage leaves an $\mathrm{NH}_{2}$-terminal Arg residue that is normally removed during intracellular processing before secretion of albumin. Consequently, the albumin of affected individuals has an additional Arg at the $\mathrm{NH}_{2}$ terminus. As with antithrombin Dublin, there is no known pathological condition associated with the albumin Redhill mutation. These naturally occurring mutations demonstrate that alterations of the amino acid sequences of signal peptides may be more common than previously thought and that, in some instances, they can have significant effects that result in diseases.

This study is the first example of a naturally occurring substitution at the -1 position of a signal peptide that results in a human disease. DNA sequence analysis revealed a substitution of Thr for Ala at the -1 position of the signal peptide. Initial inspection of the amino acid sequence of the signal peptide of the mutant preproVP did not suggest an obvious reason why this substitution should cause a problem. Amino acids at the -1 position are very important for establishing a good context for effective cleavage by signal peptidase and amino acids with small, neutral side chains are preferred at the -1 and -3 amino acid positions (30). A compilation of 161 unique eukaryotic signal peptide sequences revealed six naturally occurring proteins with $\mathrm{Thr}$ at the -1 position, so $\mathrm{Thr}$ is permissible in the context of some signal peptide sequences (30). However, according to a study of systematic substitutions of Ala at the -1 position of preproapolipoprotein with 13 amino acids (31), some differences were observed between the cleavage sites experimentally determined and those theoretically predicted based upon rules of von Heijne (30). It was also shown that inefficient signal peptidase cleavages occurred, even if the substituted amino acids were supposed to be preferable at the -1 position (e.g., Thr, Gly, Ser).

The results of our examination revealed that $\mathrm{Thr}$ at the -1 position of preproVP is an unfavorable residue in the context of this signal peptide sequence. Cell-free translation in the presence of microsomes resulted in glycosylation of the majority of the proteins synthesized as inferred from the increase in molecular weight. Since core glycosylation of secretory proteins must occur within the lumen of the endoplasmic reticulum and since the products of cell-free protein synthesis obtained in these experiments could be sedimented with microsomal vesicles, we concluded that the mutant preproVP had been effectively targeted to the interior of the vesicles. However, the mutation significantly reduced the efficiency of cleavage by signal peptidase because the major product that accumulated in the cotranslational assays was uncleaved, glycosylated preproVP. Fewer than $25 \%$ of the translocated preproVP molecules were cleaved by signal peptidase, yielding proVP. When signal peptidase cleavage occurred, it was at the normal site.

The potential fate of the uncleaved, glycosylated preproVP molecules was not addressed by this study but it is likely that these hormone precursors will remain anchored to the lipid bilayer of the endoplasmic reticulum via the uncleaved signal peptide and will not proceed through the secretory pathway for further processing. In the similar case of Factor $\mathrm{X}_{\text {Santo Domingo }}$, the uncleaved precursor protein remains in an intracellular compartment where it does not undergo further specific proteolysis but is slowly degraded (13). The aberrant, membranebound preproVP may be degraded by the proteolysis system in the endoplasmic reticulum which degrades proteins that fail to fold correctly or that fail to correctly assemble into native oligomeric complexes. Abnormal proteins retained in the endoplasmic reticulum are usually degraded (32).

Even if the mutant allele produced no VP at all, one would expect the normal allele to produce sufficient VP to prevent DI. In Brattleboro rats, where inheritance of DI displays an autosomal recessive mode, elimination of one VP allele does not result in overt DI (33). DI occurs in rats homozygous for the mutation. However, patients examined in this study have only one defective VP allele yet they represented complete DI. Accordingly, it appears unlikely that inefficiency of cleavage of the mutant preproVP alone can directly explain a VP deficiency severe enough to result in complete $\mathrm{DI}$ in this pedigree unless production of the abnormal, uncleaved preproVP has some further negative effect. Such a negative effect could result if the uncleaved precursor is not rapidly degraded and remains associated with the endoplasmic reticulum. Continued synthesis of this aberrant membrane-bound protein could ultimately interfere with normal synthesis and targeting of other secretory and membrane proteins, including normal VP precursor. Such a mechanism could ultimately lead to destruction of the cell. This degradative mechanism is consistent with the observation 
that the clinical symptoms of familial CDI do not become apparent in the affected individuals until several months to years after birth (4-6), as we have observed in this pedigree.

In conclusion, a mutation that results in the substitution of Thr for Ala at the -1 position of the signal peptide of preproVP has been identified which cosegregates with clinical DI in a pedigree of familial CDI. Cell-free analysis of this mutant secretory protein has demonstrated the molecular effect of the mutation. Targeting and translocation of the nascent preproVP to the endoplasmic reticulum are not measurably affected whereas cleavage by signal peptidase is impaired. The precise mechanism by which inefficient cleavage of preproVP contributes to the pathogenesis of DI remains to be studied.

\section{Acknowledgments}

We are grateful to Dr. Nobuhiko Suganuma, Department of Obstetrics and Gynecology, Nagoya University School of Medicine, Japan, and Dr. Hiromitsu Yuasa, First Department of Internal Medicine, Nagoya University School of Medicine, Japan, for helpful suggestions, and to Dr. Mariana Morris, Department of Physiology and Pharmacology, Bowman Gray School of Medicine of Wake Forest University, and Dr. Alan G. Robinson, Department of Medicine, University of Pittsburgh School of Medicine, for providing us the anti-rat neurophysin antibodies.

This work was supported in part by grant-in-aid 03671142 for Scientific Research from the Ministry of Education, Science, and Culture of Japan (Y. Oiso) and grant GM32861 from the National Institutes of Health (M. O. Lively).

\section{References}

1. Riddell, D. C., R. Mallonee, J. A. Phillips, J. S. Parks, L. A. Sexton, and J. L. Hamerton. 1985. Chromosomal assignment of human sequences encoding arginine vasopressin-neurophysin II and growth hormone releasing factor. Somatic Cell Mol. Genet. 11:189-195.

2. Sausville, E., D. Carney, and J. Battey. 1985. The human vasopressin gene is linked to the oxytocin gene and is selectively expressed in a cultured lung cancer cell line. J. Biol. Chem. 260:10236-10241.

3. Brownstein, M. J., J. T. Russel, and H. Gainer. 1980. Synthesis, transport, and release of posterior pituitary hormones. Science (Wash. DC). 207:373-378.

4. Baylis, P. H., and G. L. Robertson. 1981. Vasopressin function in familial cranial diabetes insipidus. Postgrad. Med. J. 57:36-40.

5. Kaplowitz, P. B., A. J. D'Ercole, and G. L. Robertson. 1982. Radioimmunoassay of vasopressin in familial central diabetes insipidus. J. Pediatr. 100:76-81.

6. Ito, M., Y. Mori, Y. Oiso, and H. Saito. 1991. A single base substitution in the coding region for neurophysin II associated with familial central diabetes insipidus. J. Clin. Invest. 87:725-728.

7. von Heijne, G. 1985. Signal sequence. The limits of variation. J. Mol. Biol 184:99-105.

8. Perlman, D., and H. O. Halvorson. 1983. A putative signal peptidase recognition site and sequence in eukaryotic and prokaryotic signal peptides. J. Mol. Biol. 167:391-409.

9. Austen, B. M. 1979. Predicted secondary structures of amino-terminal extension sequences of secreted proteins. FEBS (Fed. Eur. Biochem. Soc.) Lett. 103:308-313.

10. von Heijne, G. 1983. Patterns of amino acids near signal-sequence cleavage sites. Eur. J. Biochem. 133:17-21.

11. Arnold, A., S. A. Horst, T. J. Gardella, H. Baba, M. A. Levine, and H. M. Kronenberg. 1990. Mutation of the signal-encoding region of the preproparathyroid hormone gene in familial isolated hypoparathyroidism. J. Clin. Invest. $86: 1084-1087$.
12. Watzke, H. H., A. Wallmark, N. Hamaguchi, P. Glardina, D. W. Stafford, and K. A. High. 1991. Factor X Santo Domingo: evidence that the severe clinical phenotype arises from a mutation blocking secretion. J. Clin. Invest. 88:16851689.

13. Racchi, M., H. H. Watzke, K. A. High, and M. O. Lively. 1993. Human coagulation factor $\mathrm{X}$ deficiency caused by a mutant signal peptide that blocks cleavage by signal peptidase but not targeting and translocation to the endoplasmic reticulum. J. Biol. Chem. 268:5735-5740.

14. Seif, S. M., A. B. Huellmantel, M. P. Platia, C. Haluszczak, and A. G. Robinson. 1977. Isolation, radioimmunoassay and physiologic secretion of rat neurophysins. Endocrinology. 100:1317-1326.

15. Sanger, F., S. Nicklen, and A. R. Coulson. 1977. DNA sequencing with chain-terminating inhibitors. Proc. Natl. Acad. Sci. USA 74:5463-5467.

16. Taylor, J. W., J. Ott, and F. Eckstein. 1985. The rapid generation of oligonucleotide-directed mutations at high frequency using phosphorothioatemodified DNA. Nucleic Acids Res. 13:8765-8785.

17. Walter, P., and G. Blobel. 1983. Preparation of microsomal membranes for cotranslational protein translocation. Methods Enzymol. 96:84-93.

18. Laemmli, U. K. 1970. Cleavage of structural proteins during the assembly of the head of bacteriophage T4. Nature (Lond.). 227:680-685.

19. Sheer, D. G., S. Yuen, J. Wong, J. Wasson, and P. M. Yuan. 1991. A modified reaction cartridge for direct protein sequencing on polymeric membranes. Biotechniques. 11:526-533.

20. Mohr, E., M. Hillers, R. Ivell, I. D. Haulica, and D. Richter. 1985. Expression of the vasopressin and oxytocin genes in human hypothalmi. FEBS (Fed. Eur. Biochem. Soc.) Lett. 193:12-16.

21. Müller, M. 1992. Proteolysis in protein import and export: signal peptide processing in eu- and prokaryotes. Experentia (Basel). 48:118-129.

22. Newsome, A. L., J. W. McLean, and M. O. Lively. 1992. Molecular cloning of a cDNA encoding the glycoprotein of hen oviduct microsomal signal peptidase. Biochem. J. 282:447-452.

23. Nothwehr, S. F., S. D. Hoeltzli, K. L. Allen, M. O. Lively, and J. I. Gordon. 1990. Residues flanking the COOH-terminal C-region of a model eukaryotic signal peptide influence the site of its cleavage by signal peptidase and the extent of coupling of its co-translational translocation and proteolytic processing in vitro. J. Biol. Chem. 265:21797-21803.

24. Cioff, J. A., K. L. Allen, M. O. Lively, and B. Kemper. 1989. Paralle effects of signal peptide hydrophobic core modifications on co-translational and post-translational cleavage by purified signal peptidase. J. Biol. Chem. 264:15052-15058.

25. Ivell, R., H. Schmale, and D. Richter. 1981. Glycosylation of the arginine vasopressin/neurophysin II common precursor. Biochem. Biophys. Res. Commun. 102:1230-1236.

26. Bahnsen, U., P. Oosting, D. F. Swaab, P. Nahke, D. Richter, and H. Schmale. 1992. A missense mutation in the vasopressin-neurophysin precursor gene cosegregates with human autosomal dominant neurohypophyseal diabetes insipidus. EMBO (Eur. Mol. Biol. Organ.) J. 11:19-23.

27. Briggs, M. S., and L. M. Glerasch. 1986. Molecular mechanisms of protein secretion: the role of the signal sequence. Adv. Protein Chem. 38:109-180.

28. Daly, M., D. Bruce, D. J. Perry, J. Price, P. L. Harper, A. O'Meara, and R. W. Carrell. 1990. Antithrombin Dublin $(-3$ Val $\rightarrow$ Glu $):$ an N-terminal variant which has an aberrant signal peptidase cleavage site. FEBS (Fed. Eur. Biochem. Soc.) Lett. 273:87-90.

29. Brennan, S. O., T. Myles, R. J. Peach, D. Donaldson, and P. M. George. 1990. Albumin Redhill ( $-1 \mathrm{Arg}, 320 \mathrm{Ala} \rightarrow \mathrm{Thr}$ ): a glycoprotein variant of human serum albumin whose precursor has an aberrant signal peptide cleavage site. Proc. Natl. Acad. Sci. USA 87:26-30.

30. von Heijne, G. 1986. A new method for predicting signal sequence cleavage sites. Nucleic Acids Res. 14:4683-4690.

31. Folz, R. J., S. F. Nothwehr, and J. I. Gordon. 1988. Substrate specificity of eukaryotic signal peptidase. Site-saturation mutagenesis at position -1 regulates cleavage between multiple sites in human pre $(\Delta$ pro $)$ apolipoprotein A-II. J. Biol. Chem. 263:2070-2078.

32. Klausner, R. D., and R. Sitia. 1990. Protein degradation in the endoplasmic reticulum. Cell. 62:611-614.

33. Valtin, H. 1977. Genetic models for hypothalamic and nephrogenic diabetes insipidus. In Disturbances in Body Fluid Osmolality. T. E. Andreoli, J. J. Grantham, and F. C. Rector, Jr., editors. American Physiological Society, Bethesda, MD. 197-215. 